\title{
Key Clinical Factors Predicting Adipokine and Oxidative Stress Marker Concentrations among Normal, Overweight and Obese Pregnant Women Using Artificial Neural Networks
}

\author{
Mario Solis-Paredes ${ }^{1,2}$, Guadalupe Estrada-Gutierrez ${ }^{3}$, Otilia Perichart-Perera ${ }^{4}$, \\ Araceli Montoya-Estrada ${ }^{5}$, Mario Guzmán-Huerta ${ }^{3}$, Héctor Borboa-Olivares ${ }^{4}$, \\ Eyerahi Bravo-Flores ${ }^{5,6}$, Arturo Cardona-Pérez ${ }^{3}$, Veronica Zaga-Clavellina ${ }^{5}$, \\ Ethel Garcia-Latorre ${ }^{2}$, Gabriela Gonzalez-Perez ${ }^{7}$ (D) , José Alfredo Hernández-Pérez ${ }^{8}$ \\ and Claudine Irles ${ }^{7, *}$
}

1 Department of Human Genetics and Genomics, Instituto Nacional de Perinatología Isidro Espinosa de los Reyes, Mexico City 11000, Mexico; msolis_83@yahoo.com.mx

2 Posgrado en Ciencias Químico-Biológicas, Escuela Nacional de Ciencias Biológicas, Instituto Politécnico Nacional, Mexico City 11340, Mexico; ethelagarcia@hotmail.com

3 Research Division, Instituto Nacional de Perinatología Isidro Espinosa de los Reyes, Mexico City 11000, Mexico; gpestrad@gmail.com (G.E.-G.); mguzmanhuerta@yahoo.com.mx (M.G.-H.); acardonadr@hotmail.com (A.C.-P.)

4 Department of Nutrition and Bioprogramming, Instituto Nacional de Perinatología Isidro Espinosa de los Reyes, Mexico City 11000, Mexico; oti_perichart@yahoo.com (O.P.-P.); h_borboa1@yahoo.com (H.B.-O.)

5 Department of Inmunobiochemistry, Instituto Nacional de Perinatología Isidro Espinosa de los Reyes, Mexico City 11000, Mexico; ara_mones@hotmail.com (A.M.-E.); eyerahiqfb@yahoo.com.mx (E.B.-F.); v.zagaclavellina@gmail.com (V.Z.-C.)

6 Posgrado en Ciencias Biológicas, Universidad Nacional Autónoma de Mexico, Mexico City 04510, Mexico

7 Department of Physiology and Cellular Development, Instituto Nacional de Perinatología Isidro Espinosa de los Reyes, Mexico City 11000, Mexico; gonzalezperez.gabriela@gmail.com

8 Centro de Investigación en Ingeniería y Ciencias Aplicadas-Instituto de Investigación en Ciencias Básicas y Aplicadas (CIICAp-IICBA), Universidad Autónoma de Morelos, Cuernavaca 62209, Mexico; alfredo@uaem.mx

* Correspondence: claudine.irles@inper.gob.mx or cloirles@gmail.com; Tel.: +52-55-5520-9900

Received: 16 October 2017; Accepted: 5 December 2017; Published: 28 December 2017

\begin{abstract}
Maternal obesity has been related to adverse neonatal outcomes and fetal programming. Oxidative stress and adipokines are potential biomarkers in such pregnancies; thus, the measurement of these molecules has been considered critical. Therefore, we developed artificial neural network (ANN) models based on maternal weight status and clinical data to predict reliable maternal blood concentrations of these biomarkers at the end of pregnancy. Adipokines (adiponectin, leptin, and resistin), and DNA, lipid and protein oxidative markers (8-oxo-2'-deoxyguanosine, malondialdehyde and carbonylated proteins, respectively) were assessed in blood of normal weight, overweight and obese women in the third trimester of pregnancy. A Back-propagation algorithm was used to train ANN models with four input variables (age, pre-gestational body mass index (p-BMI), weight status and gestational age). ANN models were able to accurately predict all biomarkers with regression coefficients greater than $R^{2}=0.945$. P-BMI was the most significant variable for estimating adiponectin and carbonylated proteins concentrations (37\%), while gestational age was the most relevant variable to predict resistin and malondialdehyde (34\%). Age, gestational age and p-BMI had the same significance for leptin values. Finally, for 8-oxo-2'-deoxyguanosine prediction, the most significant variable was age (37\%). These models become relevant to improve clinical and nutrition interventions in prenatal care.
\end{abstract}


Keywords: artificial neural networks; pregnancy; oxidative stress markers; adipokines; obesity

\section{Introduction}

Obesity during pregnancy is associated with adverse maternal and neonatal outcomes, and with a higher risk of developing cardiovascular and metabolic diseases in childhood and adult stages. Maternal programming of disease has been widely described [1-9]. In particular, obesity programming of the offspring has been postulated to occur periconceptionally and at the end of pregnancy, when an increase in lipid and leptin expression is observed (reviewed by [4]). Maternal obesity is linked to dysregulation of adipose tissue (AT) metabolism [8], and an imbalance in the pro-oxidant-antioxidant system with an increase of reactive oxygen species (ROS) that results in oxidative stress [10-13]. ROS alter different cellular components such as proteins, lipids and DNA, generating oxidized biomolecules that can be used as biomarkers of oxidative stress. Carbonylated proteins (CP), malondialdehyde (MDA) and the oxidized base 8-oxo-2'-deoxyguanosine (8-oxodG) are indicators of protein oxidation, lipid peroxidation and DNA oxidation, respectively [13].

Several studies in pregnancy have linked increased oxidative stress with lower birth weight [14,15], impaired growth, and higher adiposity in infants [16]. Moreover, maternal AT secretes adipokines such as leptin, adiponectin and resistin $[17,18]$, which have been implicated in metabolic control and fetal programming of adiposity in newborns and infants [19-23]. Thus, quantification of maternal adipokines and oxidized biomolecules could be used as potential biomarkers of perinatal and infant health outcomes [24,25]. Accordingly, prenatal mathematical modeling to predict these biomarkers during pregnancy without blood sampling becomes critical to implement strategies to improve maternal and neonatal outcomes. Artificial Intelligence, particularly artificial neural network (ANN), is a powerful and rigorous tool for the analysis of non-linear and highly complex relationships that learns from all data including experimental and clinical variables, by allowing a very accurate estimation of parameters [26,27]. ANN has been applied in the perinatal field for diagnosis, data mining and clinical decision [28-32]. However, currently no mathematical models have been reported that predict maternal blood biomarkers from clinical and anthropometric data.

Consequently, the aim of this study was to develop and validate ANN models to predict blood concentrations of adipokines and oxidative stress biomarkers at the end of pregnancy based on pre-gestational weight status and clinical data. Secondly, we calculated the relative importance of these factors in estimating the biochemical values. The third trimester of pregnancy was chosen for the estimation of maternal biomarkers, since it is considered a critical window for developmental programming by maternal obesity, distinct from early pregnancy [4].

\section{Results}

We studied pregnant women during the last trimester of pregnancy (normal weight $n=25$, overweight $n=21$, obesity $n=22$ ). Mean GA when biochemical measurements were done was $35.2 \pm 3.3$ weeks. Table 1 shows maternal anthropometric and biochemical data by BMI classification. Normal weight women were younger compared to obese women and had significantly higher concentrations of adiponectin and resistin together with lower MDA and CP levels $(p<0.05)$. 
Table 1. Clinical characteristics and biochemical data in peripheral maternal blood classified according to pre-gestational BMI.

\begin{tabular}{cccc}
\hline Variables & Normal $(\boldsymbol{n = 2 5 )}$ & Overweight $(\boldsymbol{n = 2 1 )}$ & Obese $(\boldsymbol{n}=\mathbf{2 2})$ \\
\hline Age $($ years $)$ & $27.9 \pm 1.90$ & $30.3 \pm 1.90$ & $32.9 \pm 1.40^{\mathrm{b}}$ \\
p-BMI $\left(\mathrm{kg} / \mathrm{m}^{2}\right)$ & $22.0 \pm 0.30$ & $27.6 \pm 0.30^{\mathrm{a}}$ & $35.1 \pm 1.00^{\mathrm{b}, \mathrm{c}}$ \\
GA $(\mathrm{weeks})$ & $34.4 \pm 0.70$ & $35.6 \pm 0.60$ & $35.8 \pm 0.70$ \\
Glucose $(\mathrm{mg} / \mathrm{dL})$ & $80.0 \pm 2.4$ & $89.4 \pm 4.60$ & $87.3 \pm 4.10$ \\
Insulin $(\mu \mathrm{IU} / \mathrm{mL})$ & $7.80 \pm 2.0$ & $10.6 \pm 1.70$ & $14.9 \pm 3.80$ \\
HOMA-IR & $1.60 \pm 0.50$ & $2.60 \pm 0.70$ & $3.80 \pm 1.20$ \\
Leptin $(\mathrm{ng} / \mathrm{mL})$ & $24.3 \pm 3.50$ & $39.7 \pm 5.60$ & $41.2 \pm 10.7$ \\
Adiponectin $(\mu \mathrm{g} / \mathrm{mL})$ & $16.2 \pm 2.30$ & $12.3 \pm 2.10$ & $9.20 \pm 1.90^{\mathrm{b}}$ \\
Resistin $(\mathrm{ng} / \mathrm{mL})$ & $23.0 \pm 3.00$ & $20.1 \pm 4.20$ & $13.4 \pm 2.20^{\mathrm{b}}$ \\
MDA (nmol/mg dry weight) & $0.12 \pm 0.006$ & $0.13 \pm 0.01$ & $0.22 \pm 0.02^{\mathrm{b}, \mathrm{c}}$ \\
CP (nmol/mg protein) & $10.0 \pm 0.40$ & $10.9 \pm 0.70$ & $16.7 \pm 1.10^{\mathrm{b}, \mathrm{c}}$ \\
8-oxodG $(\mathrm{ng} / \mathrm{mL})$ & $218 \pm 18.4$ & $198 \pm 8.90$ & $188 \pm 4.30$
\end{tabular}

p-BMI: pregestational body mass index; GA: gestational age; MDA: malondialdehyde; CP: carbonylated proteins; 8-oxodG: 8-hydroxy-2'-deoxyguanosine. Values represent mean \pm SEM (Standard Error of the Mean). $p$ values were estimated using one-way ANOVA with DMS post hoc test. ${ }^{\mathrm{a}} p<0.05$ overweight versus normal; ${ }^{\mathrm{b}} p<0.05$ obese versus normal; ${ }^{\mathrm{c}} p<0.05$ obese versus overweight.

In this study, mathematical models with neural networks were developed to: (1) predict the concentration of either leptin, adiponectin, resistin, 8-oxodG, MDA and CP in maternal blood at the third trimester of pregnancy (output variable) through a simple equation based on four input variables: pre-gestational maternal age, $\mathrm{p}$-BMI, weight status classification and gestational age at which the sample was taken; and (2) to obtain the most critical pre-gestational parameters influencing the predicted biomarkers.

ANN neurons are organized into multiple connected layers to predict a response. The chosen architecture of the model was an input layer, a hidden layer and an output layer, trained and tested by a back-propagation algorithm (BPNN), as previously described [29]. The percentage of the experimental database (input and output variables) for training and validation was defined. For each model, from one to several neurons were applied in the hidden layer until the minimum root mean square error (RMSE) was obtained between experimental data and predicted values from the neural network (Figure 1). The Levenberg-Marquardt algorithm was chosen for training the model by changing the weights and biases to get the lowest value for the RMSE and being careful to avoid over fitting. The ANN was developed by software toolbox Matlab ${ }^{\circledR}$.

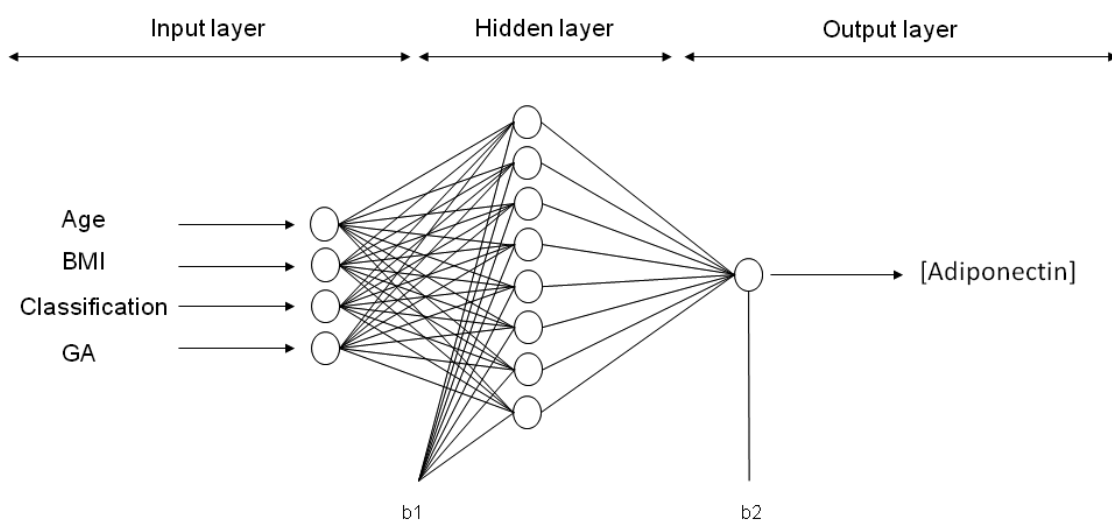

Figure 1. Maternal artificial neural network model. Shown is a representative prediction model for maternal blood adiponectin concentration involving four input variables (maternal age, p-BMI, weight status classification and gestational age), eight neurons in the hidden layer and one output variable (adiponectin concentration). 
After running distinct conditions, the hyperbolic tangential (TANSIG) transfer function presented the best performance in the hidden layer for all models. In the output layer, the Log-sigmoid (LOGSIG) transfer function was applied for adiponectin, resistin, leptin, and 8-oxodG, while the linear (PURELIN) transfer function was used for MDA and CP.

Six ANN models were trained with maternal input variables (age, p-BMI, weight status and GA) to predict the output variable: Either adiponectin, leptin, resistin, $\mathrm{CP}, \mathrm{MDA}$ or 8-oxodG concentration in maternal blood at the third trimester of pregnancy. After applying 30,000 runs (with 1000 epochs in each model) in the hidden layer (1-9 neurons), the best network architecture performances were found for each adipokine or oxidative stress marker estimation. For ANN models predicting the values of adiponectin, leptin and CP, the final architecture was 4-8-1 (four input variables, eight neurons in the hidden layer, and one neuron in the output layer (biomarker concentration)). The final topology for the MDA model was 4-6-1, while, for resistin and 8-oxodG models, the best performance was 4-9-1. The representative neural architecture for the prediction of adiponectin concentration is shown in Figure 2, whereas the weights, biases and equations for the prediction of all adipokines and oxidative stress marker concentrations are reported in Materials and Methods and Appendix A (Tables A1-A6).

a

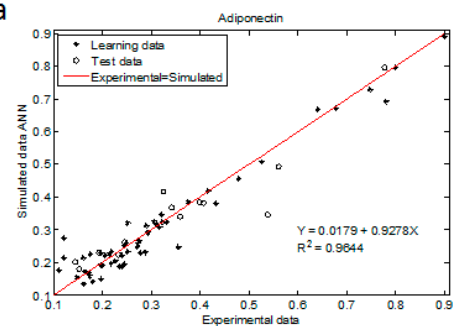

d

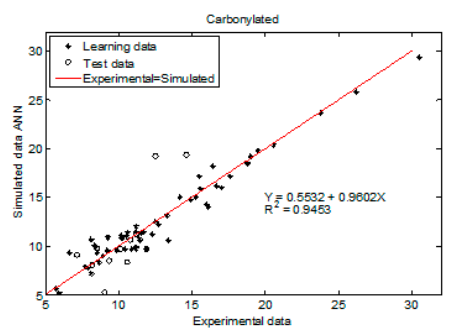

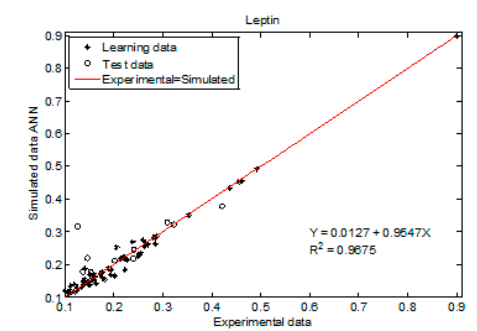

e

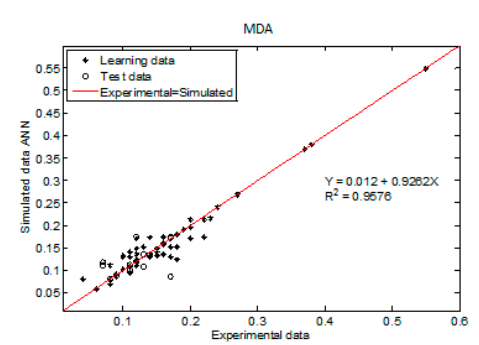

c

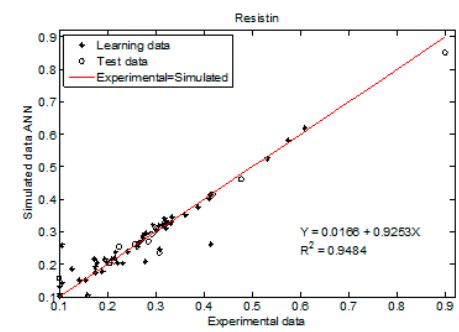

f

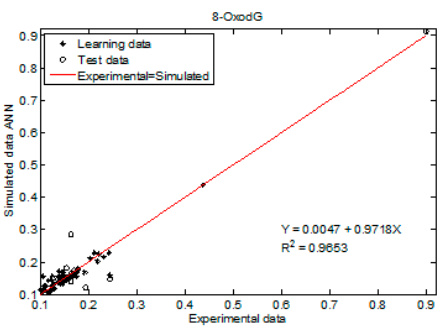

Figure 2. Experimental vs. ANN-simulated values for blood adipokine and oxidative marker concentrations. Scatter plots of: (a) adiponectin; (b) leptin; (c) resistin; (d) carbonylated proteins; (e) MDA; and (f) 8-oxodG maternal levels. Red lines indicate the linear regression model on scatter points. Open circles and closed diamonds depict experimental data and learning data, respectively.

The regression coefficient for all ANN models were above $0.945\left(R^{2}>0.9644\right.$ for adiponectin, $R^{2}>0.9675$ for leptin, $R^{2}>0.9484$ for resistin, $R^{2}>0.9453$ for $C P, R^{2}>0.9576$ for MDA and $R^{2}>0.9653$ for 8-oxodG (Figure 3)). The statistical test from these plots showed that the upper and lower values of the slope and intercept included 1 and contained 0, respectively, with a 99.9\% confidence level for all determinations (Materials and Methods and Tables A7 and A8 in Appendix A). 
a

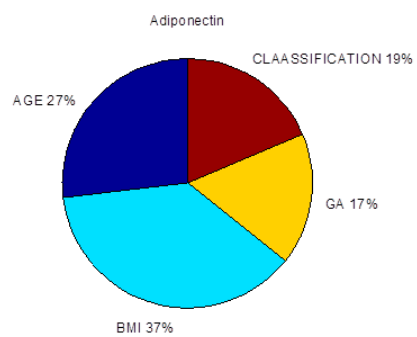

d

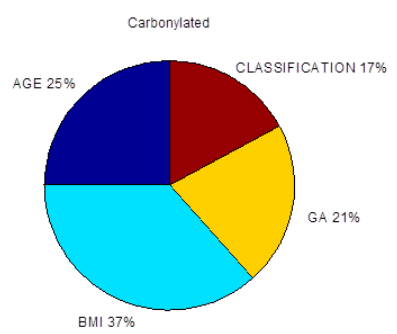

b

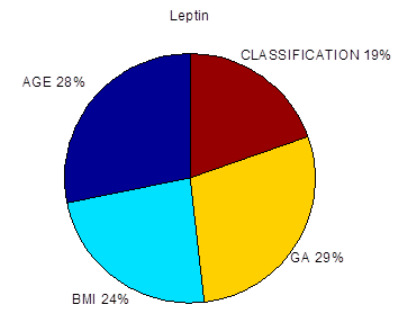

e

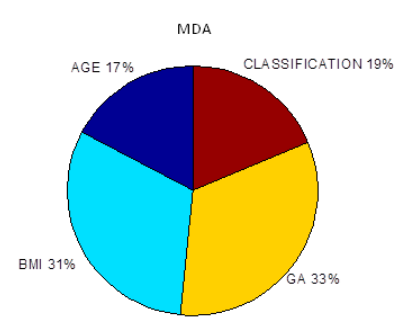

C
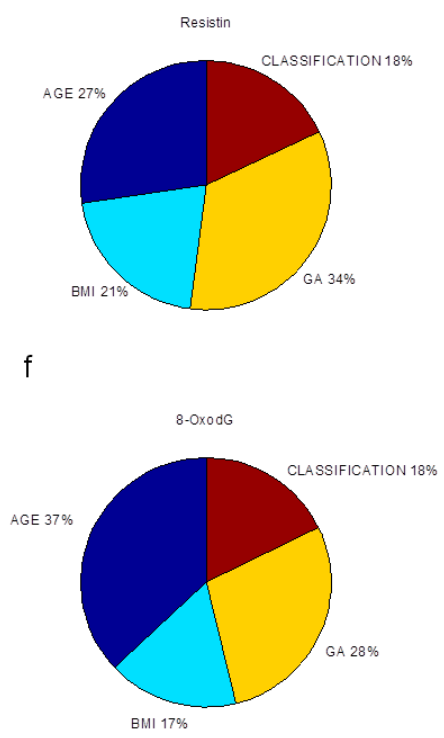

Figure 3. Sensitivity analysis. Percentage of mathematical significance of the four pre-gestational input variables (maternal age, p-BMI, weight status classification and gestational age) in maternal ANN models for: (a) adiponectin; (b) leptin; (c) resistin; (d) carbonylated proteins; (e) MDA; and (f) 8-oxodG concentrations.

Finally, we evaluated the relative importance of pre-gestational variables in the neural network modeling of adipokine and oxidative stress marker concentrations, depicted as the percentage of quantitative significance (Figure 3). The sensitivity analysis is based on the ANN weight matrix and the Garson equation [33] (Materials and Methods). All maternal factors were essential in estimating the studied biochemical markers. P-BMI was the most important predictor of adiponectin followed by age. For leptin prediction, age, GA and p-BMI value had the same importance. The most relevant factor in forecasting resistin was GA; other predictor factors were age and $\mathrm{p}$-BMI value. For oxidative markers, GA and p-BMI estimated MDA, while $\mathrm{CP}$ were predominantly predicted by $\mathrm{p}-\mathrm{BMI}$, followed by age and GA. Finally, for 8-oxodG, the meaningful variable was age, then GA and p-BMI. Weight status was the weakest predictor in all models.

\section{Discussion}

Nutrition and metabolic changes occur during pregnancy to promote optimal fetal growth and development. The presence of obesity in pregnancy is associated with nutrient and hormonal imbalances, and with inflammation [34]. Altered leptin, adiponectin, and oxidative stress markers have been documented in pregnant women with obesity [25,35], and have been associated with adverse perinatal outcomes [36-38]. The early prediction of alterations in these markers at the end of pregnancy is very relevant, considering the high prevalence of overweight/obesity in women of reproductive age in many countries [39].

ANN is a tool that allowed the estimation of these biochemical markers with anthropometric and clinical variables that are generally used in clinical practice. We present six ANN models that accurately predict third trimester maternal concentrations of adipokines (adiponectin, leptin, and resistin) and DNA, lipid and protein oxidative damage markers (8-oxodG, MDA and CP, respectively). Regression coefficients between the experimental and predicted values for all determinations were superior to $\mathrm{R}^{2}=0.945$.

For adipokines, the model correctly estimated higher leptin concentrations together with lower adiponectin and resistin values in obese mothers in comparison with normal and overweight pregnant 
women, a finding that has been reported before $[25,40]$. In particular, the ANN-predicted adiponectin values (that learned from the experimental data) were similar to those found in the literature [41].

We found that leptin prediction was equally dependent on GA, p-BMI and maternal age. This is in agreement with the literature where leptin concentration increases with gestational age in normal pregnancies, mainly produced by adipose tissue, placenta, skeletal muscle and mammary gland (reviewed by [42]). Many studies also have shown increased leptin concentrations with higher p-BMI and in overweight/obese women [35,43,44].

Maternal adiponectin has been inversely related with BMI [45], GA and positively associated with maternal age $[46,47]$. The ANN adiponectin model derived from this study was able to predict these associations too. P-BMI was the most important parameter in estimating adiponectin and carbonylated proteins.

Pregnancy per se is an oxidative stress condition due to a higher oxygen demand [48]. Protein carbonylation is caused by the direct attack of free radicals, by interaction with transition metals, by glycation or by adduct formation with final lipoperoxidation products (MDA) (reviewed by [49]). In our models, CP and MDA estimated values were significantly increased in obese pregnancies compared to normal weight mothers, suggesting an increased oxidative damage in the latter and in line with the literature [24,50]. In this work, a higher p-BMI was related to decreased adiponectin and increased MDA concentrations, in agreement with a negative correlation between adiponectin and oxidative lipid damage during pregnancy [51].

Gestational age at sample collection was a relevant factor (34\%) for resistin and MDA predictions, suggesting that resistin and MDA levels are greatly influenced by gestational age at the end of pregnancy, despite differences in maternal BMI. These results could be explained by the resistin-dependent insulin resistance that is increased during pregnancy and is modulated in part by a higher glucose transporter 1 (GLUT-1) expression in trophoblast cells induced by resistin [52].

Concerning oxidative damage markers, there is a physiological increase associated with women's aging [53] as well as with advanced gestational age in normal pregnancies [54]. Interestingly, for 8-oxodG, the meaningful variable was maternal age (37\%). The link between oxidative stress and aging has been discussed in recent years. In human clinical cohorts, increased 8-oxodG levels in muscle and leukocyte DNA were observed with increasing age [55]. No studies have been reported in pregnancy. Investigating changes in this DNA oxidative marker during pregnancy in different age groups is pending.

\section{Study Limitations and Strengths}

A limitation of this study is the sample size $(n=68)$, however, the model accurately estimated blood concentrations with regression coefficients with values $>0.9$. Furthermore, other ANN studies have shown validated results with smaller samples [30]. It is important to mention that these ANN models will predict accurately adipokines and oxidative stress markers within the range in which they learn, for example healthy women with singleton pregnancy, maternal p-BMI range between 18.6 and $48.3 \mathrm{~kg} / \mathrm{m}^{2}$.

\section{Materials and Methods}

\subsection{Study Design and Ethical Approval}

This research was approved by the IRB of the Instituto Nacional de Perinatología Isidro Espinosa de los Reyes (register 3300-11402-01-575-17), and was conducted according to the relevant national regulations and the Helsinki Declaration with its later amendments (1985). Participation was voluntary and all women who agreed to participate signed an informed consent. 


\subsection{Characteristics of the Population}

Healthy women with singleton pregnancy, and with blood sample taken during the third trimester of gestation (28-40 weeks of gestation) were enrolled in the study $(n=68)$. Samples were selected by convenience and stratified by pregestational body mass index (p-BMI). Gestational age (GA) was determined using the last menstrual period date; if GA with this method differed significantly from first trimester ultrasound measurement, then the latter was used. Women with multiple pregnancies, Type 2 Diabetes Mellitus or gestational diabetes mellitus, chronic or gestational hypertension, renal or autoimmune disease, intrauterine fetal growth restriction, fetal structural abnormalities or drug intake that affects metabolism and/or inflammation (metformin, steroids, insulin, and antihypertensives, among others) were excluded.

\subsection{Anthropometry}

Pre-gestational weight was self-reported. Stature $(\mathrm{cm})$ was measured with a stadiometer (SECA 220, Hamburg, Germany) by trained personnel. P-BMI was calculated using the following formula: Weight/stature ${ }^{2}$. BMI classification was done according to the World Health Organization criteria, where a p-BMI $>18.5$ was classified as normal weight, $\mathrm{p}-\mathrm{BMI}>25$ as overweight, and $>30$ as obesity.

\subsection{Biochemical Markers}

Maternal blood samples were collected in the fasting state, in Vacutainer tubes (Becton-Dickinson, Franklin Lakes, NJ, USA) and centrifuged at $4{ }^{\circ} \mathrm{C}$ for $15 \mathrm{~min}$ at $1000 \times \mathrm{g}$. The serum and plasma samples were stored at $-80^{\circ} \mathrm{C}$ until the assays were performed.

Serum glucose, adiponectin, leptin, resistin, and insulin concentrations were measured by ELISA commercial kits, as previously described [20]. Adiponectin, leptin and resistin (R \& D Systems Inc., Minneapolis, MN, USA) had the following sensitivities: $0.891 \mathrm{ng} / \mathrm{mL}, 7.8 \mathrm{ng} / \mathrm{mL}$ and $0.055 \mathrm{ng} / \mathrm{mL}$, respectively; and assay ranges: $3.9-250 \mathrm{ng} / \mathrm{mL} ; 15.6-1000 \mathrm{pg} / \mathrm{mL}$ and $0.2-10 \mathrm{ng} / \mathrm{mL}$, respectively. Insulin (Sigma-Aldrich, St. Louis, MO, USA) and glucose (DiaSys Diagnostic Systems GmbH, Holzheim, Germany) sensitivities were: $2.15 \mathrm{pmol} / \mathrm{L}$, and $1 \mathrm{mg} / \mathrm{dL}$, respectively; and assay ranges were: $15.6-500 \mathrm{pmol} / \mathrm{mL}$ and $1-400 \mathrm{mg} / \mathrm{dL}$, respectively.

Homeostatic model assessment (HOMA) index was calculated according to [56]. Oxidative DNA damage level was measured using an 8-oxodG ELISA kit (TREVIGEN, Gaithersburg, MD, USA) with a sensitivity and assay range of $0.57 \mathrm{ng} / \mathrm{mL}$ and $0.89-56.7 \mathrm{ng} / \mathrm{mL}$, respectively. Plasma malondialdehyde (MDA) was quantified as described by Gerard et al. [57] with 1-methyl-2-phenylindole (Sigma-Aldrich, St. Louis, MO, USA) as a standard. Sensitivity for MDA determination was $17 \mathrm{ng} / \mathrm{mL}$ and assay range of $0.27-2000 \mathrm{ng} / \mathrm{mL}$. Protein damage was evaluated by plasma carbonyl group content, which was determined with 2,4-dinitrophenylhydrazine (DNPH), and measured according to Amici et al. [58]. Assay range and sensitivity for $\mathrm{CP}$ evaluation were: $1-10 \mathrm{mg} / \mathrm{mL}$ and $1.5 \mathrm{nmol} / \mathrm{mg}$, respectively.

\subsection{Statistical Analysis}

Descriptive analysis (data distribution, frequencies) were done. One-way ANOVA with DMS post hoc test was used to analyze differences by p-BMI categories (normal weight, overweight or obese). Data are expressed as mean $\pm \mathrm{SEM}$, and $p$ values $\leq 0.05$ were considered statistically significant. Statistical analysis was performed using the IBM SPSS v20.0 software (IBM Corporation, Armonk, NY, USA).

\subsection{ANN (Learning, Testing and Validation)}

An artificial neural network utilizes nodes (neurons) connected between each other in distinct layers, their relationship being defined by weights $(W i, W o)$ and biases $(b 1, b 2)$ that are obtained by iterations with the ANN algorithm. Figure 4 depicts a representative architecture for the neural network model (multi-layer) with an input layer, a hidden layer and an output layer, trained and 
tested by a Back-propagation algorithm (BPNN). The ANN is "fed" randomly with the database and calculates the error between the experimental and predicted values. Then, it back propagates changing the weights and biases to obtain the smallest error. For all the models, the input variables chosen from the entire database were four maternal parameters: Age, p-BMI, weight status (normal weight, overweight, or obese) and GA at which maternal blood sample was taken. The output maternal variable was one biomarker: leptin, adiponectin, resistin, 8-oxodG, MDA or CP concentrations at the third trimester of pregnancy (input and output variables are depicted in Table 2).

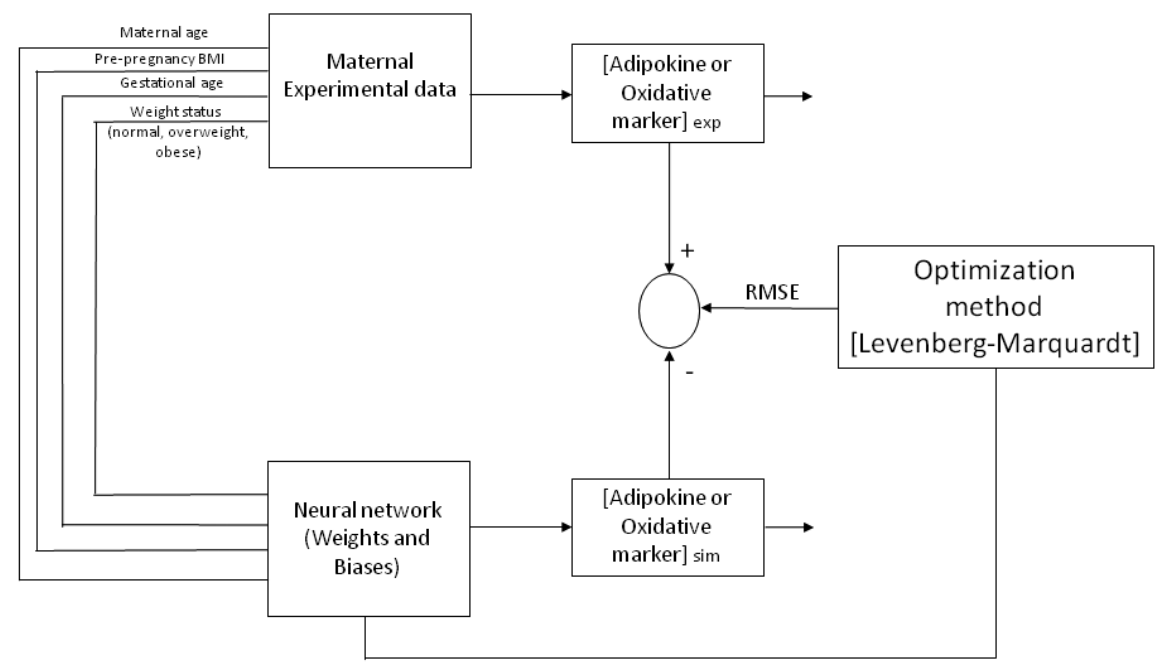

Figure 4. A representative network architecture of the maternal artificial neural network (ANN) model. The learning procedure used by ANN for the prediction at the third trimester of pregnancy of adipokine or oxidative stress marker concentrations in maternal blood (from 4 gestational variables: maternal age, p-BMI, weight status classification and gestational age), trained by the Levenberg-Marquardt optimization algorithm. The same architecture was utilized for adiponectin, leptin, resistin, carbonylated proteins, MDA and 8-oxodG values estimation. + and - indicate changing the weights and biases values to obtain the smallest error between exp and sim.

Table 2. Input (clinical and anthropometric variables) and output (biochemical values) range conditions in the maternal ANN model.

\begin{tabular}{cccc}
\hline Input Variables & Range & Output Variables & Range \\
\hline Age (years) & $14-43$ & Leptin $(\mathrm{ng} / \mathrm{mL})$ & $0.38-223.4$ \\
p-BMI $\left(\mathrm{kg} / \mathrm{m}^{2}\right)$ & $18.6-48.3$ & Adiponectin $(\mu \mathrm{g} / \mathrm{mL})$ & $4.1-40.4$ \\
GA (weeks) & $28.3-40.4$ & Resistin $(\mathrm{ng} / \mathrm{mL})$ & $0.7-90.4$ \\
& & MDA (nmol/mg dry weight) & $0.04-0.55$ \\
Weight Status Classification & Normal, overweight or obese & 8-oxodG $(\mathrm{ng} / \mathrm{mL})$ & $160-642$ \\
& & $\mathrm{CP}(\mathrm{nmol} / \mathrm{mg}$ protein) & $5.72-30.5$ \\
\hline
\end{tabular}

p-BMI: pregestational body mass index; GA: gestational age; MDA: malondialdehyde; CP: carbonylated proteins; 8-oxodG: 8-hydroxy-2'-deoxyguanosine.

\subsubsection{ANN Model}

The experimental database $(n=68)$ was randomly divided into learning $(79 \%)$ and validation $(21 \%)$ and then, the input variables were normalized in the range of 0.1 to 0.9 , as previously described [29]. The output variable was not normalized.

Each neuron $(n)$ has weights ( $W i$ and $W o$ ) and biases ( $b 1$ and $b 2)$ in the hidden and output layers (1) and (2):

$$
n_{1}=W i \times I n_{1}+W i \times I n_{2}+\ldots \ldots+W i \times I n_{k}+b 1
$$


where $I n$ is the input variable. The value of each neuron is the argument of the transfer functions $(f$ and $g$ ):

$$
\text { Adipokine or oxidative stress marker (output) }=g(\text { Wo } \times f(W i \times I n+b 1)+b 2)
$$

where $f$ is a hyperbolic tangent transfer function (TANSIG) and $g$ is a linear transfer function (PURELIN) or Log-Sigmoid function (LOGSIG).

We applied different transfer functions to obtain the best performance for the models. As a result of the ANN model, Equation (2) with TANSIG-PURELIN was Equation (3):

$$
\text { output }=\sum_{s}\left\{W o_{(l, s)} \cdot\left[\frac{2}{1+e^{-2 \cdot\left(\sum_{k} W i_{(s, k)} \cdot \ln n_{k}+b 1_{(s, 1)}\right)}}-1\right]\right\}+b 2_{(l, 1)}
$$

For other ANN models, Equation (2) considering TANSIG-LOGSIG was Equation (4), where $n_{\text {output }}$ is:

$$
\begin{aligned}
& \text { output }=\frac{1}{\left(1+\exp \left(-n_{\text {output_layer })}\right)\right.} \\
& n_{\text {output_layer }}=\sum_{s}\left\{W o_{(l, s)} \cdot\left[\frac{2}{1+e^{-2 \cdot\left(\sum_{k} W i_{(s, k)} \cdot \ln n_{k}+b 1_{(s, 1)}\right)}}-1\right]\right\}+b 2_{(l, 1)}
\end{aligned}
$$

\subsubsection{ANN Learning}

In this work, to change the weights and biases, we applied the Levenberg-Marquardt (LM) algorithm, following our previously reported methods [29]. This uses the adaptation as follows:

$$
\Delta w=\left(J^{T} J+\mu I\right)^{-1} J^{T} e
$$

where $J$ is the Jacobian matrix (first derivative); $e$ is a vector of network errors; $\mu$ is the combination coefficient with a value of 0.001 and $I$ is the identity matrix.

The root mean square error (RMSE) was applied as the error function which describes the performance of the network according to the following Equation (6):

$$
R M S E=\sqrt{\frac{\left(\sum_{q=1}^{Q}\left(y_{q, \exp }-y_{q, A N N s i m}\right)^{2}\right)}{Q}}
$$

where $Q$ is the number of data points $(n=68)$; $y_{q, \exp }$ is the experimental data and $y_{q, A N N s i m}$ is the network prediction.

4.6.3. Results for Maternal Adipokines and Oxidative Stress Marker ANN Models

The proposed ANN models for MDA and CP followed Equation (7) with TANSIG-PURELIN:

$$
M D A(\text { or }) C P_{-} \text {concentration }=\sum_{s=1}^{S}\left[W o_{(1, s)}\left(\frac{2}{1+\exp \left(-2\left(\sum_{k=1}^{K}\left(W i_{(s, k)} I n_{(k)}\right)+b 1_{(s)}\right)\right)}-1\right)\right]+b 2_{(1)}
$$

Equation (8) gives adiponectin, leptin, resistin and 8-oxodG with TANSIG-LOGSIG, where $n_{\text {output }}$ is:

$$
\begin{aligned}
& \text { adiponectin_or_resistin_or_leptin_or } 8-\text { oxod } G=\frac{1}{\left(1+\exp \left(-n_{\text {output_layer }}\right)\right)} \\
& n_{\text {output_layer }}=\sum_{s}\left\{W o_{(l, s)} \cdot\left[\frac{2}{1+e^{-2 \cdot\left(\sum_{k} W i_{(s, k)} \cdot I n_{k}+b 1(s, 1)\right)}}-1\right]\right\}+b 2_{(l, 1)}
\end{aligned}
$$


Equations (7) and (8) give the maternal adipokine or oxidative stress marker concentrations with weights and biases in Table A1 (Adiponectin ANN model, 4-8-1), Table A2 (Leptin ANN model, 4-8-1), Table A3 (Resistin ANN model, 4-9-1), Table A4 (carbonylated proteins ANN model, 4-8-1), Table A5 (MDA ANN model, 4-6-1) and Table A6 (8-oxodG ANN model, 4-9-1) in Appendix A.

\subsubsection{Statistical Tests for ANN Model Validation}

ANN model validation was performed using linear regression models of the experimentally measured adipokines and oxidative stress marker concentrations versus the simulated ones (learning and validation database), obtaining the slope and intercept (Figure 3). Then, we applied a statistical test (slope and intercept, [59]) in which the upper and lower intervals of the slope and intercept must be near 1.0 and 0 respectively, with a $99.8 \%$ confidence level according to the Student $t$-test.

The regression coefficient $\left(R^{2}\right)$ was then obtained from linear regression models for each biochemical value:

$$
\text { (Adipokine }_{\text {sim }} \text { or Redox marker } \text { sim }=a+b \text { Adipokine or Redox } \text { marker }_{\text {exp }} \text { ) }
$$

\subsection{Sensitivity Analysis}

To obtain the relative biological importance of maternal variables in predicting adipokine and oxidative stress marker concentrations, we performed a sensitivity analysis, as proposed by [33], based on the partitioning of connection weights:

$$
I_{j}=\frac{\sum_{m=1}^{N h}\left(\left(\frac{\left|W_{j m}^{i h}\right|}{\sum_{k=1}^{N i}\left|W_{k m}^{i h}\right|}\right) \times\left|W_{m n}^{h o}\right|\right)}{\sum_{k=1}^{N i}\left\{\sum_{m=1}^{N h}\left(\frac{\left|W_{k m}^{i h}\right|}{\sum_{k=1}^{N i}\left|W_{k m}^{i h}\right|}\right) \times\left|W_{m n}^{h o}\right|\right\}}
$$

where $I_{j}$ is the relative importance of the input variable on the output variable; $N_{i}$ is the number of input neurons; $N_{h}$ is the number of hidden neurons; $W$ is the connection weight; and the superscripts $i, h$ and $o$ refer to input, hidden and output layer.

\section{Conclusions}

The ANN models accurately predicted adipokine and oxidative stress marker concentrations in the third trimester of pregnancy based on feasible and easy to measure clinical and anthropometric variables, allowing to obtain the reference blood concentrations in pregnant women with or without pre-pregnancy overweight and obesity. The early prediction of alterations in these markers (prenatal) could be used by clinicians to implement strategies that improve metabolic and nutrition status, influencing perinatal outcomes in overweight/obese women. The prediction of these maternal biomarkers adds quantitative dimensions to the assessment of pregnancy follow-up, which could particularly benefit the group of patients with normal pregnancy outcomes despite abnormal adipokine and oxidative stress marker concentrations. Alterations in these markers may modify nutrient utilization by the fetus, and thus, impact fetal growth. Being large for gestational age or macrosomic at birth is associated with higher adiposity later in life. Consequently, the prediction of these alterations early in pregnancy may guide clinicians in selecting different strategies to improve nutrition and monitor fetal growth closely. Studies are in progress to evaluate if the models may be generalized to other settings.

Acknowledgments: We would like to acknowledge the support from the INPer (grant numbers: 3300-11402-01-575-17 and 2017-2-65). This work was funded in part by Consejo Nacional de Ciencia y Tecnología (CONACyT), Fondo Sectorial en Salud (grant number 86840) to OPP. MSP was sponsored by CONACyT. 
Author Contributions: Claudine Irles, Mario Solis-Paredes, Guadalupe Estrada-Gutierrez, and José Alfredo Hernández-Pérez conceived and designed the study. Mario Solis-Paredes, Eyerahi Bravo-Flores, Héctor Borboa-Olivares, and Mario Guzmán-Huerta recruited patients. Guadalupe Estrada-Gutierrez, Mario Solis-Paredes, Araceli Montoya-Estrada, and Eyerahi Bravo-Flores performed the experiments. Mario Solis-Paredes and Araceli Montoya-Estrada performed statistical analysis. Mario Solis-Paredes, Guadalupe Estrada-Gutierrez, Arturo Cardona-Pérez, Otilia Perichart-Perera, Veronica Zaga-Clavellina, Gabriela Gonzalez-Perez, Mario Guzmán-Huerta, Héctor Borboa-Olivares, Ethel García Latorre, José Alfredo Hernández-Pérez, and Claudine Irles wrote the manuscript. All authors read and approved the manuscript.

Conflicts of Interest: Otilia Perichart-Perera is a speaker/consultant at the Nestlé Nutrition Institute in Mexico City. All other authors declare that there is no conflict of interest.

\section{Abbreviations}

$\begin{array}{ll}\text { ANN } & \text { Artificial neural network } \\ \text { p-BMI } & \text { Pre-pregnancy Body Mass Index } \\ \text { CP } & \text { Carbonylated proteins } \\ \text { 8-oxodG } & \text { oxidized base 8-oxo-2' } \text {-deoxyguanosine }^{\text {MDA }} \\ \text { MA } & \text { Malondialdehyde } \\ \text { GA } & \text { Gestational age } \\ \text { CP } & \text { Carbonylated proteins } \\ \text { MA } & \text { Maternal age }\end{array}$

\section{Appendix A}

Weight and biases for ANN models.

Table A1. Weights and biases for the ANN model predicting adiponectin concentration.

\begin{tabular}{|c|c|c|c|c|c|c|c|c|}
\hline \multicolumn{9}{|c|}{8 Neurons on Hidden Layer $(k=8$ and $l=1)$} \\
\hline \multirow{9}{*}{$W i_{\{s, k\}}$} & $W i_{\{s, 1\}}$ & $W i_{\{s, 2\}}$ & $W i_{\{s, 3\}}$ & $W i_{\{s, 4\}}$ & & & & \\
\hline & -0.052517 & 3.7407 & 0.30914 & -0.83713 & & & & \\
\hline & -28.294 & -6.5884 & 1.4140 & 11.300 & & & & \\
\hline & -6.9433 & 4.7470 & -20.738 & 2.7172 & & & & \\
\hline & -1.4014 & -1.2418 & 2.5042 & 2.3499 & & & & \\
\hline & 12.935 & -11.478 & 7.3280 & 6.8132 & & & & \\
\hline & 3.3992 & 6.2892 & -2.5518 & -4.9357 & & & & \\
\hline & 9.3624 & -10.582 & 4.9177 & 6.7825 & & & & \\
\hline & 4.0123 & 27.372 & 10.360 & 3.5215 & & & & \\
\hline \multirow{2}{*}{$W o_{\{l, s\}}$} & $W o\{1,1\}$ & $W o_{\{1,2\}}$ & $W o_{\{1,3\}}$ & $W o_{\{1,4\}}$ & $W o_{\{1,5\}}$ & $W o_{\{1,6\}}$ & $W o_{\{1,7\}}$ & $W o_{\{1,8\}}$ \\
\hline & 4.0988 & 10.884 & -0.96316 & -5.4384 & -6.5596 & -2.8140 & 7.3260 & -13.678 \\
\hline \multirow{9}{*}{$b 1_{\{s, 1\}}$} & $b 1_{\{5,1\}}$ & & & & & & & \\
\hline & -0.45666 & & & & & & & \\
\hline & 24.442 & & & & & & & \\
\hline & 12.415 & & & & & & & \\
\hline & -1.3457 & & & & & & & \\
\hline & -6.3817 & & & & & & & \\
\hline & -1.6500 & & & & & & & \\
\hline & -4.2754 & & & & & & & \\
\hline & -7.4087 & & & & & & & \\
\hline$b 2_{\{l, s\}}$ & $\begin{array}{c}b 2_{\{1,1\}} \\
-0.54830\end{array}$ & & & & & & & \\
\hline
\end{tabular}


Table A2. Weights and biases for the ANN model predicting leptin concentration.

\begin{tabular}{|c|c|c|c|c|c|c|c|c|}
\hline \multicolumn{9}{|c|}{8 Neurons on Hidden Layer $(k=8$ and $l=1)$} \\
\hline \multirow{9}{*}{$W i_{\{s, k\}}$} & $W i_{\{s, 1\}}$ & $W i_{\{s, 2\}}$ & $W i_{\{s, 3\}}$ & $W i_{\{s, 4\}}$ & & & & \\
\hline & -2.1829 & 0.79377 & -8.8924 & -4.8956 & & & & \\
\hline & 13.941 & 7.3074 & 9.7328 & -0.5 .0633 & & & & \\
\hline & 12.187 & -14.506 & -16.893 & -12.973 & & & & \\
\hline & 47.113 & -32.460 & -16.992 & -19.329 & & & & \\
\hline & -18.396 & 7.7265 & 5.3903 & -15.068 & & & & \\
\hline & -19.657 & -21.542 & 10.787 & 14.645 & & & & \\
\hline & -16.118 & 26.497 & -1.4738 & 2.4320 & & & & \\
\hline & 0.17226 & -3.3014 & 7.6009 & 6.3612 & & & & \\
\hline \multirow{2}{*}{$W o_{\{l, s\}}$} & $W o_{\{1,1\}}$ & $W o_{\{1,2\}}$ & $W o_{\{1,3\}}$ & $W o_{\{1,4\}}$ & $W o_{\{1,5\}}$ & $W o_{\{1,6\}}$ & $W o_{\{1,7\}}$ & $W o_{\{1,8\}}$ \\
\hline & -2.2859 & 2.1313 & 1.0830 & -0.93728 & -2.0859 & & 0.46330 & -2.5751 \\
\hline \multirow{9}{*}{$b 1_{\{s, 1\}}$} & $b 1_{\{5,1\}}$ & & & & & & & \\
\hline & 7.0867 & & & & & & & \\
\hline & -22.895 & & & & & & & \\
\hline & 19.031 & & & & & & & \\
\hline & 10.810 & & & & & & & \\
\hline & -2.7510 & & & & & & & \\
\hline & -2.7589 & & & & & & & \\
\hline & 6.3961 & & & & & & & \\
\hline & -5.1093 & & & & & & & \\
\hline$b 2_{\{l, s\}}$ & $\begin{array}{l}b 2_{\{1,1\}} \\
2.2934\end{array}$ & & & & & & & \\
\hline
\end{tabular}

Table A3. Weights and biases for the ANN model predicting resistin concentration.

\begin{tabular}{|c|c|c|c|c|c|c|c|c|c|}
\hline & & $9 \mathrm{Neu}$ & ons on $\mathrm{Hi}$ & den Layer & $(k=9$ an & $l=1)$ & & & \\
\hline$W i_{\{s, k\}}$ & $\begin{array}{c}W i_{\{s, 1\}} \\
-0.12216 \\
27.276 \\
-0.49141 \\
16.723 \\
12.611 \\
-0.69780 \\
-0.11218 \\
-8.4773 \\
3.6918\end{array}$ & $\begin{array}{c}W i_{\{s, 2\}} \\
-6.136 \\
11.076 \\
-1.0027 \\
-1.2056 \\
8.6390 \\
2.7485 \\
9.3635 \\
2.8179 \\
1.3614\end{array}$ & $\begin{array}{c}W i_{\{s, 3\}} \\
2.6049 \\
-2.3404 \\
1.6407 \\
16.100 \\
-1.4910 \\
-60.73 \\
-14.79 \\
-10.031 \\
9.154\end{array}$ & $\begin{array}{c}W i_{\{s, 4\}} \\
9.6953 \\
-5.9354 \\
-0.2277 \\
-3.8005 \\
8.5175 \\
1.1423 \\
6.7889 \\
0.56276 \\
-5.7361\end{array}$ & & & & & \\
\hline$W o_{\{l, s\}}$ & $\begin{array}{l}W o_{\{1,1\}} \\
7.5398\end{array}$ & $\begin{array}{l}W o_{\{1,2\}} \\
12.500\end{array}$ & $\begin{array}{l}W o_{\{1,3\}} \\
6.2809\end{array}$ & $\begin{array}{c}W o_{\{1,4\}} \\
-5.7172\end{array}$ & $\begin{array}{l}W o_{\{1,5\}} \\
9.6729\end{array}$ & $\begin{array}{l}W o_{\{1,6\}} \\
10.140\end{array}$ & $\begin{array}{c}W o_{\{1,7\}} \\
-0.10398\end{array}$ & $\begin{array}{l}W o_{\{1,8\}} \\
-6.2219\end{array}$ & $\begin{array}{l}W o_{\{1,9\}} \\
6.4819\end{array}$ \\
\hline$b 1_{\{s, 1\}}$ & $\begin{array}{c}b 1_{\{5,1\}} \\
0.5 .1064 \\
-24.66 \\
0.68847 \\
-12.01 \\
-0.0111 \\
1.0737 \\
-9.0268 \\
6.8763 \\
-2.4130\end{array}$ & & & & & & & & \\
\hline$b 2_{\{l, s\}}$ & $\begin{array}{c}b 2_{\{1,1\}} \\
0.81976\end{array}$ & & & & & & & & \\
\hline
\end{tabular}


Table A4. Weights and biases for the ANN model predicting carbonylated proteins concentration.

\begin{tabular}{|c|c|c|c|c|c|c|c|c|}
\hline \multicolumn{9}{|c|}{8 Neurons on Hidden Layer $(k=8$ and $l=1)$} \\
\hline$W i_{\{s, k\}}$ & $\begin{array}{c}W i_{\{s, 1\}} \\
-3.4952 \\
-14.758 \\
2.0876 \\
-0.67465 \\
-28.741 \\
7.6510 \\
-5.0850 \\
-33.142\end{array}$ & $\begin{array}{c}W i_{\{s, 2\}} \\
-24.375 \\
-2.6467 \\
-11.504 \\
-5.0937 \\
-10.542 \\
-25.181 \\
-1.6182 \\
-33.116\end{array}$ & $\begin{array}{c}W i_{\{s, 3\}} \\
-4.9253 \\
-8.7481 \\
5.7321 \\
-3.3881 \\
14.773 \\
9.7527 \\
-3.9322 \\
12.653\end{array}$ & $\begin{array}{c}W i_{\{s, 4\}} \\
-5.3093 \\
3.5794 \\
-0.96934 \\
2.6267 \\
31.069 \\
-0.41751 \\
0.55163 \\
33.422\end{array}$ & & & & \\
\hline$W o_{\{l, s\}}$ & $\begin{array}{l}W o_{\{1,1\}} \\
5.5379\end{array}$ & $\begin{array}{l}W o_{\{1,2\}} \\
9.0540\end{array}$ & $\begin{array}{c}W o_{\{1,3\}} \\
-35.747\end{array}$ & $\begin{array}{c}W o_{\{1,4\}} \\
-37.903\end{array}$ & $\begin{array}{l}W o_{\{1,5\}} \\
-33.806\end{array}$ & $\begin{array}{l}W o_{\{1,6\}} \\
32.181\end{array}$ & $\begin{array}{c}W o_{\{1,7\}} \\
-10.788\end{array}$ & $\begin{array}{l}W o_{\{1,8\}} \\
36.050\end{array}$ \\
\hline$b 1_{\{s, 1\}}$ & $\begin{array}{c}b 1_{\{5,1\}} \\
3.7180 \\
9.8466 \\
1.5882 \\
9.3072 \\
-12.59 \\
2.2808 \\
4.2440 \\
-2.7282\end{array}$ & & & & & & & \\
\hline$b 2_{\{l, s\}}$ & $\begin{array}{l}b 2_{\{1,1\}} \\
15.546\end{array}$ & & & & & & & \\
\hline
\end{tabular}

Table A5. Weights and biases for the ANN model predicting MDA concentration.

\begin{tabular}{|c|c|c|c|c|c|c|}
\hline \multicolumn{7}{|c|}{6 Neurons on Hidden Layer $(k=6$ and $l=1)$} \\
\hline$W i_{\{s, k\}}$ & $\begin{array}{c}W i_{\{s, 1\}} \\
-12.646 \\
-7.3917 \\
7.7847 \\
-7.2892 \\
0.33297 \\
2.8826\end{array}$ & $\begin{array}{c}W i_{\{s, 2\}} \\
5.3087 \\
22.045 \\
-4.6160 \\
21.445 \\
22.854 \\
-1.1998\end{array}$ & $\begin{array}{c}W i_{\{s, 3\}} \\
30.714 \\
-16.992 \\
7.8948 \\
-17.128 \\
-20.959 \\
4.1718\end{array}$ & $\begin{array}{c}W i_{\{s, 4\}} \\
-3.5685 \\
12.924 \\
2.3106 \\
13.605 \\
-4.7038 \\
0.65482\end{array}$ & & \\
\hline$W o_{\{l, s\}}$ & $\begin{array}{c}W o_{\{1,1\}} \\
0.07501\end{array}$ & $\begin{array}{c}W o_{\{1,2\}} \\
-3.1628\end{array}$ & $\begin{array}{c}W o_{\{1,3\}} \\
0.30868\end{array}$ & $\begin{array}{l}W o_{\{1,4\}} \\
3.1815\end{array}$ & $\begin{array}{c}W o_{\{1,5\}} \\
0.06675\end{array}$ & $\begin{array}{c}W o_{\{1,6\}} \\
-1.7149\end{array}$ \\
\hline$b 1_{\{s, 1\}}$ & $\begin{array}{c}b 1_{\{5,1\}} \\
-14.317 \\
-5.8818 \\
-11.299 \\
-5.9995 \\
5.4172 \\
-6.5706\end{array}$ & & & & & \\
\hline$b 2_{\{l, s\}}$ & $\begin{array}{c}b 2_{\{1,1\}} \\
-1.2413\end{array}$ & & & & & \\
\hline
\end{tabular}


Table A6. Weights and biases for the ANN model predicting 8-oxodG concentration.

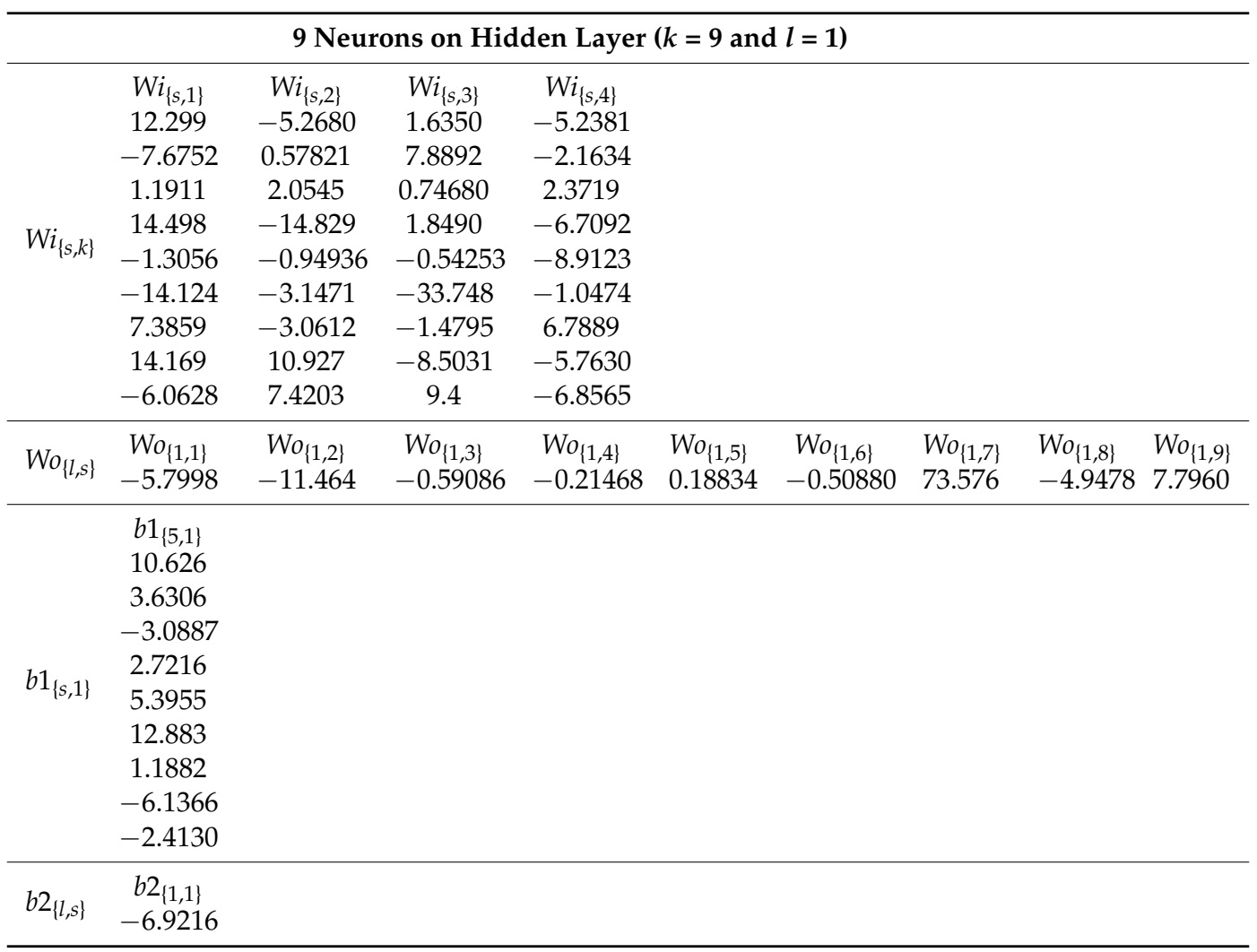

Table A7. Slope and intercept values for adipokines statistical test.

\begin{tabular}{cccccc}
\hline \multicolumn{2}{c}{ Adiponectin } & \multicolumn{2}{c}{ Leptin } & \multicolumn{2}{c}{ Resistin } \\
\hline$a_{\text {lower }}$ & $a_{\text {upper }}$ & $a_{\text {lower }}$ & $a_{\text {upper }}$ & $a_{\text {lower }}$ & $a_{\text {upper }}$ \\
-0.0189 & 0.0546 & -0.0124 & 0.0378 & -0.0200 & 0.0531 \\
$b_{\text {lower }}$ & $b_{\text {upper }}$ & $b_{\text {lower }}$ & $b_{\text {upper }}$ & $b_{\text {lower }}$ & $b_{\text {upper }}$ \\
0.8270 & 1.0287 & 0.8558 & 1.0535 & 0.8027 & 1.0480 \\
\hline
\end{tabular}

Table A8. Slope and intercept values for oxidative stress markers statistical test.

\begin{tabular}{cccccc}
\hline \multicolumn{2}{c}{ Carbonylated Proteins } & \multicolumn{2}{c}{ MDA } & \multicolumn{2}{c}{ 8-oxodG } \\
\hline$a_{\text {lower }}$ & $a_{\text {upper }}$ & $a_{\text {lower }}$ & $a_{\text {upper }}$ & $a_{\text {lower }}$ & $a_{\text {upper }}$ \\
-1.1971 & 1.3036 & -0.0075 & 0.0314 & -0.0159 & 0.0254 \\
$b_{\text {lower }}$ & $b_{\text {upper }}$ & $b_{\text {lower }}$ & $b_{\text {upper }}$ & $b_{\text {lower }}$ & $b_{\text {upper }}$ \\
0.8289 & 1.0916 & 0.8158 & 1.0367 & 0.8677 & 1.0760 \\
\hline
\end{tabular}

\section{References}

1. Barnes, S.K.; Ozanne, S.E. Pathways linking the early environment to long-term health and lifespan. Prog. Biophys. Mol. Biol. 2011, 106, 323-336. [CrossRef] [PubMed]

2. Drake, A.J.; Reynolds, R.M. Impact of maternal obesity on offspring obesity and cardiometabolic disease risk. Reproduction 2010, 140, 387-398. [CrossRef] [PubMed]

3. Gaillard, R. Maternal obesity during pregnancy and cardiovascular development and disease in the offspring. Eur. J. Epidemiol. 2015, 30, 1141-1152. [CrossRef] [PubMed]

4. Nicholas, L.M.; Morrison, J.L.; Rattanatray, L.; Zhang, S.; Ozanne, S.E.; McMillen, I.C. The early origins of obesity and insulin resistance: Timing, programming and mechanisms. Int. J. Obes. 2016, 40, 229-238. [CrossRef] [PubMed] 
5. Poston, L. Developmental programming and diabetes-The human experience and insight from animal models. Best Pract. Res. Clin. Endocrinol. Metab. 2010, 24, 541-552. [CrossRef] [PubMed]

6. Remmers, F.; Delemarre-van de Waal, H.A. Developmental programming of energy balance and its hypothalamic regulation. Endocr. Rev. 2011, 32, 272-311. [CrossRef] [PubMed]

7. Symonds, M.E.; Sebert, S.P.; Hyatt, M.A.; Budge, H. Nutritional programming of the metabolic syndrome. Nat. Rev. Endocrinol. 2009, 5, 604-610. [CrossRef] [PubMed]

8. Zambrano, E.; Ibanez, C.; Martinez-Samayoa, P.M.; Lomas-Soria, C.; Durand-Carbajal, M.; Rodriguez-Gonzalez, G.L. Maternal Obesity: Lifelong Metabolic Outcomes for Offspring from Poor Developmental Trajectories during the Perinatal Period. Arch. Med. Res. 2016, 47, 1-12. [CrossRef] [PubMed]

9. Zambrano, E.; Nathanielsz, P.W. Mechanisms by which maternal obesity programs offspring for obesity: Evidence from animal studies. Nutr. Rev. 2013, 71 (Suppl. S1), S42-S54. [CrossRef] [PubMed]

10. Marseglia, L.; Manti, S.; D'Angelo, G.; Nicotera, A.; Parisi, E.; di Rosa, G.; Gitto, E.; Arrigo, T. Oxidative stress in obesity: A critical component in human diseases. Int. J. Mol. Sci. 2015, 16, 378-400. [CrossRef] [PubMed]

11. McMurray, F.; Patten, D.A.; Harper, M.E. Reactive Oxygen Species and Oxidative Stress in Obesity-Recent Findings and Empirical Approaches. Obesity 2016, 24, 2301-2310. [CrossRef] [PubMed]

12. Horn, R.C.; Gelatti, G.T.; Mori, N.C.; Tissiani, A.C.; Mayer, M.S.; Pereira, E.A.; Ross, M.; Moreira, P.R.; Bortolotto, J.W.; Fellippin, T. Obesity, bariatric surgery and oxidative stress. Rev. Assoc. Med. Bras. 2017, 63, 229-235. [CrossRef] [PubMed]

13. Powers, S.K.; Jackson, M.J. Exercise-induced oxidative stress: Cellular mechanisms and impact on muscle force production. Physiol. Rev. 2008, 88, 1243-1276. [CrossRef] [PubMed]

14. Kim, Y.J.; Hong, Y.C.; Lee, K.H.; Park, H.J.; Park, E.A.; Moon, H.S.; Ha, E.H. Oxidative stress in pregnant women and birth weight reduction. Reprod. Toxicol. 2005, 19, 487-492. [CrossRef] [PubMed]

15. Min, J.; Park, B.; Kim, Y.J.; Lee, H.; Ha, E.; Park, H. Effect of oxidative stress on birth sizes: Consideration of window from mid pregnancy to delivery. Placenta 2009, 30, 418-423. [CrossRef] [PubMed]

16. Loy, S.L.; Sirajudeen, K.N.; Hamid Jan, J.M. The effects of prenatal oxidative stress levels on infant adiposity development during the first year of life. J. Dev. Orig. Health Dis. 2014, 5, 142-151. [CrossRef] [PubMed]

17. Houshmand-Oeregaard, A.; Hansen, N.S.; Hjort, L.; Kelstrup, L.; Broholm, C.; Mathiesen, E.R.; Clausen, T.D.; Damm, P.; Vaag, A. Differential adipokine DNA methylation and gene expression in subcutaneous adipose tissue from adult offspring of women with diabetes in pregnancy. Clin. Epigenet. 2017, 9, 37-49. [CrossRef] [PubMed]

18. Luo, L.; Liu, M. Adipose tissue in control of metabolism. J. Endocrinol. 2016, 231, R77-R99. [CrossRef] [PubMed]

19. Castro, N.P.; Euclydes, V.V.; Simoes, F.A.; Vaz-de-Lima, L.R.; de Brito, C.A.; Luzia, L.A.; Devakumar, D.; Rondó, P.H. The Relationship between Maternal Plasma Leptin and Adiponectin Concentrations and Newborn Adiposity. Nutrients 2017, 9, 182. [CrossRef] [PubMed]

20. Solis-Paredes, M.; Espino y Sosa, S.; Estrada-Gutierrez, G.; Nava-Salazar, S.; Ortega-Castillo, V.; Rodriguez-Bosch, M.; Bravo-Flores, E.; Espejel-Nuñez, A.; Tolentino-Dolores, M.; Gaona-Estudillo, N.; et al. Maternal and Fetal Lipid and Adipokine Profiles and Their Association with Obesity. Int. J. Endocrinol. 2016, 2016, 7015626. [CrossRef] [PubMed]

21. Donnelly, J.M.; Lindsay, K.L.; Walsh, J.M.; Horan, M.; Molloy, E.J.; McAuliffe, F.M. Fetal metabolic influences of neonatal anthropometry and adiposity. BMC Pediatr. 2015, 15, 175. [CrossRef] [PubMed]

22. Lemas, D.J.; Brinton, J.T.; Shapiro, A.L.; Glueck, D.H.; Friedman, J.E.; Dabelea, D. Associations of maternal weight status prior and during pregnancy with neonatal cardiometabolic markers at birth: The Healthy Start study. Int. J. Obes. 2015, 39, 1437-1442. [CrossRef]

23. Perng, W.; Gillman, M.W.; Mantzoros, C.S.; Oken, E. A prospective study of maternal prenatal weight and offspring cardiometabolic health in midchildhood. Ann. Epidemiol. 2014, 24, 793-800. [CrossRef] [PubMed]

24. Hernandez-Trejo, M.; Montoya-Estrada, A.; Torres-Ramos, Y.; Espejel-Nunez, A.; Guzman-Grenfell, A.; Morales-Hernandez, R.; Tolentino-Dolores, M.; Laresgoiti-Servitje, E. Oxidative stress biomarkers and their relationship with cytokine concentrations in overweight/obese pregnant women and their neonates. BMC Immunol. 2017, 18, 3. [CrossRef] [PubMed] 
25. Vernini, J.M.; Moreli, J.B.; Costa, R.A.; Negrato, C.A.; Rudge, M.V.; Calderon, I.M. Maternal adipokines and insulin as biomarkers of pregnancies complicated by overweight and obesity. Diabetol. Metab. Syndr. 2016, 8 , 68-76. [CrossRef] [PubMed]

26. Bishop, C.M. Neural networks and their applications. Rev. Sci. Instrum. 1994, 65, 1803-1832. [CrossRef]

27. McCulloch, W.S.; Pitts, W. A logical calculus of the ideas immanent in nervous activity. Bull. Math. Biol. 1990, 52, 99-115. [CrossRef] [PubMed]

28. Walker, C.R.; Frize, M. Are artificial neural networks "ready to use" for decision making in the neonatal intensive care unit? Pediatr. Res. 2004, 56, 6-8. [CrossRef] [PubMed]

29. Guzman-Barcenas, J.; Hernandez, J.A.; Arias-Martinez, J.; Baptista-Gonzalez, H.; Ceballos-Reyes, G.; Irles, C. Estimation of umbilical cord blood leptin and insulin based on anthropometric data by means of artificial neural network approach: Identifying key maternal and neonatal factors. BMC Pregnancy Childbirth 2016, 16, 179. [CrossRef] [PubMed]

30. Street, M.E.; Grossi, E.; Volta, C.; Faleschini, E.; Bernasconi, S. Placental determinants of fetal growth: Identification of key factors in the insulin-like growth factor and cytokine systems using artificial neural networks. BMC Pediatr. 2008, 8, 24. [CrossRef] [PubMed]

31. Grossi, E.; Buscema, M. Artificial intelligence and outcome research. Drug Dev. Res. 2006, 67, $227-244$. [CrossRef]

32. Christodoulakis, G.; Marias, K.; Notas, G.; Kampanis, N.; Sfakianakis, S. A Technological Platform to Support Education in Regional Anaesthesia with Patient-Specific Virtual Physiological Human (VPH)-Based Models. In Proceedings of the XIV Mediterranean Conference on Medical and Biological Engineering and Computing, Paphos, Cyprus, 31 March-2 April 2016; Kyriacou, E., Christofides, S., Pattichis, C., Eds.; IFMBE Proceeding; Springer: Basel, Switzerland, 2016; Volume 57, pp. 932-935. [CrossRef]

33. Garson, G.D. Interpreting neural-network connection weights. AI Expert 1991, 6, 47-51.

34. Challier, J.C.; Basu, S.; Bintein, T.; Minium, J.; Hotmire, K.; Catalano, P.M.; Haugel-de Mouson, S. Obesity in pregnancy stimulates macrophage accumulation and inflammation in the placenta. Placenta 2008, 29, 274-281. [CrossRef] [PubMed]

35. Hendler, I.; Blackwell, S.C.; Mehta, S.H.; Whitty, J.E.; Russell, E.; Sorokin, Y.; Cotton, D.B. The levels of leptin, adiponectin, and resistin in normal weight, overweight, and obese pregnant women with and without preeclampsia. Am. J. Obstet. Gynecol. 2005, 193, 979-983. [CrossRef] [PubMed]

36. Vernini, J.M.; Moreli, J.B.; Magalhaes, C.G.; Costa, R.A.A.; Rudge, M.V.C.; Calderon, I.M.P. Maternal and fetal outcomes in pregnancies complicated by overweight and obesity. Reprod. Health 2016, 8, 68-76. [CrossRef] [PubMed]

37. Minsart, A.F.; Buekens, P.; de Spiegelaere, M.; Englert, Y. Neonatal outcomes in obese mothers: A population-based analysis. BMC Pregn. Child. 2013, 13, 36. [CrossRef] [PubMed]

38. Koch, L. Obesity: Effect of maternal obesity on neonatal outcomes. Nat. Rev. Endocrinol. 2013, 9, 439. [CrossRef] [PubMed]

39. Ng, M.; Fleming, T.; Robinson, M.; Thomson, B.; Graetz, N.; Margono, C.; Mullany, E.C.; Biryukov, S.; Abbafati, C.; Abera, S.F.; et al. Global, regional, and national prevalence of overweight and obesity in children and adults during 1980-2013: A systematic analysis for the Global Burden of Disease Study 2013. Lancet 2014, 384, 766-781. [CrossRef]

40. Fujimori, M.; Franca, E.L.; Morais, T.C.; Fiorin, V.; de Abreu, L.C.; Honorio-Franca, A.C. Cytokine and adipokine are biofactors can act in blood and colostrum of obese mothers. Biofactors 2017, 43, $243-250$. [CrossRef] [PubMed]

41. Zembala-Szczerba, M.; Jaworowski, A.; Huras, H.; Babczyk, D.; Jach, R. Low-Grade Metabolically-Induced Inflammation Mediators Interleukin-6, Adiponectin, and TNF- $\alpha$ Serum Levels in Obese Pregnant Patients in the Perinatal Period. Med. Sci. Monit. Basic Res. 2017, 23, 1-7. [CrossRef] [PubMed]

42. Pendeloski, K.P.T.; Ono, E.; Torloni, M.R.; Mattar, R.; Daher, S. Maternal obesity and inflammatory mediators: A controversial association. Am. J. Reprod. Immunol. 2017, 77, e12674. [CrossRef] [PubMed]

43. Carlhall, S.; Bladh, M.; Brynhildsen, J.; Claesson, I.M.; Josefsson, A.; Sydsjo, G.; Thorsell, A.; Blomberg, M. Maternal obesity (Class I-III), gestational weight gain and maternal leptin levels during and after pregnancy: A prospective cohort study. BMC Obes. 2016, 3, 28. [CrossRef] [PubMed] 
44. Perichart-Perera, O.; Munoz-Manrique, C.; Reyes-Lopez, A.; Tolentino-Dolores, M.; Espino y Sosa, S.; Ramirez-Gonzalez, M.C. Metabolic markers during pregnancy and their association with maternal and newborn weight status. PLoS ONE 2017, 12, e0180874. [CrossRef] [PubMed]

45. Baden, M.Y.; Yamada, Y.; Takahi, Y.; Obata, Y.; Saisho, K.; Tamba, S.; Yamamoto, K.; Umeda, M.; Furubayashi, A.; Tsukamoto, Y.; et al. Association of adiponectin with blood pressure in healthy people. Clin. Endocrinol. 2013, 78, 226-231. [CrossRef] [PubMed]

46. Obata, Y.; Yamada, Y.; Takahi, Y.; Baden, M.Y.; Saisho, K.; Tamba, S.; Yamamoto, K.; Umeda, M.; Furubayashi, A.; Matsuzawa, Y. Relationship between serum adiponectin levels and age in healthy subjects and patients with type 2 diabetes. Clin. Endocrinol. 2013, 79, 204-210. [CrossRef] [PubMed]

47. Tomono, Y.; Hiraishi, C.; Yoshida, H. Age and sex differences in serum adiponectin and its association with lipoprotein fractions. Ann. Clin. Biochem. 2017, 1, 4563217699233. [CrossRef] [PubMed]

48. Gitto, E.; Reiter, R.J.; Karbownik, M.; Tan, D.-X.; Gitto, P.; Barberi, S.; Barberi, I. Causes of Oxidative Stress in the Pre- and Perinatal Period. Biol. Neonate 2002, 81, 146-157. [CrossRef] [PubMed]

49. Yin, H.; Xu, L.; Porter, N.A. Free radical lipid peroxidation: Mechanisms and analysis. Chem. Rev. 2011, 111, 5944-5972. [CrossRef] [PubMed]

50. Malti, N.; Merzouk, H.; Merzouk, S.A.; Loukidi, B.; Karaouzene, N.; Malti, A.; Narce, M. Oxidative stress and maternal obesity: Feto-placental unit interaction. Placenta 2014, 35, 411-416. [CrossRef] [PubMed]

51. Eleuterio, N.M.; Palei, A.C.T.; Machado, J.S.R.; Tanus-Santos, J.E.; Cavalli, R.C.; Sandrim, V.C. Role of adiponectin on antioxidant profile: Evaluation during healthy and hypertensive disorders of pregnancy. Blood Press. 2016, 25, 241-243. [CrossRef] [PubMed]

52. Illsley, N.P. Glucose transporters in the human placenta. Placenta 2000, 21, 14-22. [CrossRef] [PubMed]

53. Gil, L.; Siems, W.; Mazurek, B.; Gross, J.; Schroeder, P.; Voss, P.; Grune, T. Age-associated analysis of oxidative stress parameters in human plasma and erythrocytes. Free Radic. Res. 2006, 40, 495-505. [CrossRef] [PubMed]

54. Wickens, D.; Wilkins, M.H.; Lunec, J.; Ball, G.; Dormandy, T.L. Free radical oxidation (peroxidation) products in plasma in normal and abnormal pregnancy. Ann. Clin. Biochem. 1981, 18 Pt 3, 158-162. [CrossRef] [PubMed]

55. Jacob, K.D.; Noren-Hooten, N.; Trzeciak, A.R.; Evans, M.K. Markers of oxidant stress that are clinically relevant in aging and age-related disease. Mech. Ageing Dev. 2013, 134, 139-157. [CrossRef] [PubMed]

56. Matthews, D.R.; Hosker, J.P.; Rudenski, A.S.; Naylor, B.A.; Treacher, D.F.; Turner, R.C. Homeostasis model assessment: Insulin resistance and $\beta$-cell function from fasting plasma glucose and insulin concentrations in man. Diabetologia 1985, 28, 412-419. [CrossRef] [PubMed]

57. Gerard-Monnier, D.; Erdelmeier, I.; Regnard, K.; Moze-Henry, N.; Yadan, J.C.; Chaudiere, J. Reactions of 1-methyl-2-phenylindole with malondialdehyde and 4-hydroxyalkenals. Analytical applications to a colorimetric assay of lipid peroxidation. Chem. Res. Toxicol. 1998, 11, 1176-1183. [CrossRef] [PubMed]

58. Amici, A.; Levine, R.L.; Tsai, L.; Stadtman, E.R. Conversion of amino acid residues in proteins and amino acid homopolymers to carbonyl derivatives by metal-catalyzed oxidation reactions. J. Biol. Chem. 1989, 264, 3341-3346. [PubMed]

59. Verma, S.P.; Andaverde, J.; Santoyo, E. Application of the error propagation theory in estimates of static formation temperatures in geothermal and petroleum boreholes. Energy Convers. Manag. 2006, 47, 3659-3671. [CrossRef]

(C) 2017 by the authors. Licensee MDPI, Basel, Switzerland. This article is an open access article distributed under the terms and conditions of the Creative Commons Attribution (CC BY) license (http://creativecommons.org/licenses/by/4.0/). 